Publisher: African Networks on Ethnomedicines

Website: //http://journals.sfu.ca/africanem/index.php /AJID

http://dx.doi.org/10.4314/ajid.v6i2.1

\title{
COMMUNITY PARTICIPATION IN MALARIA CONTROL IN OLORUNDA LOCAL GOVERNMENT AREA, OSUN STATE, SOUTHWESTERN NIGERIA
}

\author{
J. O. Bamidele ${ }^{1}$, M. I. Ntaji ${ }^{2}$, E. A. Oladele ${ }^{3}$ and O. K. Bamimore ${ }^{3}$ \\ ${ }^{1}$ LAUTECH College of Health Sciences, Osogbo, Osun State, Nigeria. \\ ${ }^{2}$ Delta State University Teaching Hospital, Oghara, Delta State, Nigeria. \\ ${ }^{3}$ LAUTECH Teaching Hospital, Osogbo, Osun State, Nigeria. \\ E-mail: bjobam@hotmail.com \& bjobam2004@yahoo.co.uk
}

\begin{abstract}
Malaria is a major health burden in developing countries and needs multiple strategies for its control. Community participation as one of the strategies for malaria control promotes self-awareness and confidence, causes the people to examine the problems and to think positively about the solutions. The study was aimed at assessing the level of community participation in malaria control in Olorunda local government area of Osogbo, Osun state, Nigeria. The study employed a cross-sectional descriptive design. Multi-staged sampling technique was used to choose 550 respondents. An intervieweradministered semi-structured questionnaire was used to elicit information from the respondents. Most of the respondents (65.0\%) fell between the age ranges $20-39$ years, with a mean age of $32.85 \pm 12$ years. Almost all (98.4\%) respondents had knowledge of malaria with most of them (88.0\%) correctly aware that mosquito bite could lead to malaria fever. Respondents stated that stagnant pool (92.6\%) and refuse dump (89.0\%) could predispose to malaria. About two-thirds (60.6\%) of the respondents participated in the control of the breeding sites of mosquitoes on specific days for environmental sanitation. The association between community participation in health talk and community participation in malaria control was statistically significant $(\mathrm{p}<0.000)$. Although only $23.0 \%$ use ITN to protect themselves from mosquito bites, there was statistical significant association between awareness of respondents about ITN and its usage $(p=0.003)$. Knowledge of respondents about malaria was high with majority participating in malaria control measures. However, the use of insecticide treated nets (ITN) was low. Therefore, it is recommended that continuous awareness creation on the use of ITN, and continued efforts aimed at elimination of breeding sites of mosquitoes should be adopted to achieve long term control of malaria.
\end{abstract}

Key words: malaria control, community participation, urban, rural communities.

\section{Introduction}

Malaria is a life threatening parasitic endemic disease in Africa. It has been identified to be a major health burden worldwide especially in the developing world, sub-Saharan Africa inclusive. The disease is one of the leading causes of death and ill health in many developing countries, where children under 5 years and pregnant women are mostly affected (Schapira, 2004). There are at least 300 million acute cases of malaria each year globally, resulting in more than a million deaths. Around $90 \%$ of these deaths occur in Africa, and nearly two-thirds occur in children under the age of 5 years (Ghosh et al., 2006; WHO, 2002). Children are especially vulnerable because they lack natural immunity to malaria and are at greater risk of developing more severe forms of the disease. The children who survive a severe bout of malaria may develop chronic anaemia and neurological impairment. Pregnant women are susceptible to malaria and it is a cause of low birth weight and infant mortality. Estimates of the disease burden due to malaria in Africa show that the toll it exacts in terms of loss of life, episodes of serious illness, and impediment to economic development is enormous (Kleinschmidt, 2001). The burden of malaria is causing many countries in Africa to sink further into poverty. In Africa today, malaria is understood to be both a disease of poverty and a cause of poverty.

Nigeria has a high prevalence of malaria (FMOH, 2001; Onwujekwe et al., 2000) and it is a leading cause of morbidity and mortality in the country (FMOH, 2001) especially among the most vulnerable groups - pregnant women, infants and children (Sridhar et al., 2004). Available records show that at least 50\% of the population in Nigeria suffer from at least one episode of malaria each year and malaria accounts for over 45 per cent of all out-patient visits (FMOH, 2001). It is reported that malaria prevalence (notified cases) in 2000 was about 2.4 million (FMOH, 2001). The disease accounts for 25 per cent of infant mortality and 30 per cent of childhood mortality in Nigeria (FMOH, 2001). Therefore, it imposes great burden on the country in terms of pains and trauma suffered by its victims as well as loss in outputs and cost of treatments (Onwujekwe et al., 2004).

Malaria is a protozoan infestation caused by the presence of the protozoan; Plasmodium in humans or other vertebrates red blood cells, usually transmitted to humans by the bite of infected female Anopheles mosquitoes that previously sucked the blood from a person with malaria (Sachs and Melaney, 2002). Malaria control activities replaced the earlier eradication and elimination efforts when it was realised that many countries were failing to achieve set targets (Rojas et al., 2001). There is now renewed global commitment which has led to the recent drive in malaria control. Due to the success of control efforts in some countries, elimination is already again being entertained in some quarters. Various control measures have been designed for adoption by individuals, communities, local government areas, states and even at the national level. Community participation plays a vital role in many of the control measures especially those designed for implementation at community level (Atkinson et al., 2009). In addition, community participation is considered one of the most important elements for the control of endemic disease in poor countries, particularly for prevention and epidemiological 
Publisher: African Networks on Ethnomedicines

Website: //http://journals.sfu.ca/africanem/index.php /AJID

http://dx.doi.org/10.4314/ajid.v6i2.1

surveillance (Dias, 1998). Community participation promotes self-awareness and confidence, causes people to examine their problems and to think positively about the solutions. It increases the sense of control over issues that affect the lives of community members in this case the scourge of malaria (Mlozi et al., 2006). Since malaria is a problem that affects the community, every community over time has had its local realities, strengths and limitations as regards managing the scourge of malaria. Community participation through harnessing local initiatives, local resources, and community mobilization and giving a sense of ownership in the control of this major health problem will play a vital role. In view of this, the study was carried out to assess the level of community participation in alleviating the burden of malaria on the populace.

\section{Methodology}

The study was carried out in Olorunda Local Government Area of Osun State, South Western, Nigeria. The study design was a descriptive cross-sectional survey. The study population consisted of adults above 18yrs old in three randomly selected communities within Olorunda LGA which include Akogun and Atelewo that are urban communities, while Ilie is a rural community. The estimated study population for the three communities was greater than 10,000 . A minimum sample size of 369 was obtained using the Fisher's formula for population greater than 10,000. After adjusting for non-response and to allow for more representative data, a total of 550 questionnaires were used for the study.

A multistage sampling technique was adopted. Three communities (Akogun, Atelewo and Ilie) were randomly selected from amongst the 11 communities/wards of the local government area using the balloting method. The number of questionnaires was proportionately allocated to each community using the population figure obtained for each ward/community according to the year 2006 National Census. In each of the communities, five streets were then randomly selected from a list of the streets presented by the Land and Housing Authority department of the Local Government Council. At the entrance of each randomly selected street of each community, a bottle was rolled, the house to which the bottle pointed was used as the first house where all adults above 18yrs that were met at home at the time of visit of the research team were interviewed and subsequently adults in every other houses were interviewed until sample size in each community was obtained.

Pretested, semi-structured questionnaires were either self-administered or administered by interviewers to selected respondents after informed consent were obtained. Information was collected on Socio-demographic status, respondent's knowledge and perception of malaria and malaria control measures, respondent's attitude and practice towards malaria control with emphasis on community participation. Collected data were checked for consistency. Analysis was done with the use of Statistical Package for Social Sciences (SPSS) version 13.0 software. The results were presented in frequency tables and chi-square was used to determine the association between relevant variables (significant level $\mathrm{p}<0.05$ ).

\section{Results}

A total of Five hundred and fifty (550) respondents were interviewed, but five hundred (500) questionnaires were sufficiently completed and analysed representing a response rate of $90.9 \%$. Table 1 shows that majority of the respondents were aged 20-29 years with a mean age of $32.85+/$ - 12years while only $15.8 \%$ of them were above the age of 50 years. About $43.4 \%$ of the respondents were males while $56.6 \%$ were females. Most of the respondents (81.8\%) had at least primary education, while the rest (18.2\%) of them had no formal education. Most of the respondents (63.4\%) were married, $0.4 \%$ was divorced and $32.8 \%$ were single. The respondents were mostly traders, artisans, students, and farmers.

Majority (98.4\%) of respondents were aware of malaria while $1.6 \%$ of respondents were not aware of malaria (Table 2). Most (88\%) of the respondents correctly identified mosquito bite as the cause of malaria, $34.2 \%$ believe bad weather can cause malaria and a few (5.6\%) felt witchcraft can cause malaria. Fever is the commonest symptom recognised by respondents (83.4\%), followed by body ache (73.8\%), chills and rigor (48.6\%) and vomiting (16.4\%). Majority of the respondents (92.6\%) were aware that stagnant pool predisposes to malaria, while $89 \%$ and $91.6 \%$ were aware that bush and refuse dump respectively also predisposes to malaria. Of the respondents, $47.0 \%$ were aware of insecticide treated nets (ITN) as a means of protection against malaria while $53.0 \%$ were not aware.

Table 3 shows that majority 494 (98.8\%) of the respondents protects themselves from mosquito bites while only 6 (1.2\%) do not. The most adopted method is the use of insecticide by $356(71.2 \%)$ of the respondents, 115 (23\%) use ITN, while the use of repellent cream is the least adopted method used by 17 (3.4\%) respondents. About 6 of every 10 respondents (60.6\%) participated in the control of breeding sites refuse dump, $45.4 \%$ cleared bushes and $44.8 \%$ of the participants drained gutters.

\section{Discussion}

Majority of the respondents (65.0\%) were found within the age groups of 20-39 years with a mean age of 32.85+/_ 12years; this age group falls within the agile population and this shows a promising target group for increased effort on community participation. Majority of the respondents $(81.0 \%)$ had at least attended primary school and being literate has a positive effect on community participation in malaria control as it helped them to have better understanding about the cause of malaria, mode of transmission, symptoms, prevention and control. Education, especially focusing on school-age children, helped clarify misconceptions that take root in the community concerning what malaria is, how it manifests itself, what produces it, how it is transmitted, and how it can be diagnosed in a timely manner and treated adequately (Rojas et al., 2001). 
Publisher: African Networks on Ethnomedicines

Website: //http://journals.sfu.ca/africanem/index.php /AJID

http://dx.doi.org/10.4314/ajid.v6i2.1

Likewise, the community grasped the basic concepts of the hazards of self-medication and incomplete treatment (Rojas et al., 2001).

Table 1: Sociodemographic characteristics of respondents $(n=500)$

\begin{tabular}{lr}
\hline Sociodemographic characteristics & Frequency (\%) \\
\hline Age (years) & $48(9.6)$ \\
$<20$ & $227(45.4)$ \\
$20-29$ & $98(19.6)$ \\
$30-39$ & $48(9.6)$ \\
$40-49$ & $79(15.8)$ \\
50 \& above & \\
$\quad$ Mean = 32.85 \pm 12years) & \\
Sex & $217(43.4)$ \\
Male & $283(56.6)$ \\
Female & \\
Educational status & $91(18.2)$ \\
No formal education & $118(23.6)$ \\
Primary & $218(43.6)$ \\
Secondary & $73(14.6)$ \\
Tertiary & \\
Marital status & $164(32.8)$ \\
Single & $317(63.4)$ \\
Married & $17(3.4)$ \\
Widowed & $2(0.4)$ \\
Divorced & \\
Occupation & $35(7.0)$ \\
Farmers & $167(33.4)$ \\
Traders & $156(31.2)$ \\
Artisans & $104(20.8)$ \\
Students & $22(4.4)$ \\
Civil servants/Professionals & $16(3.2)$ \\
Unemployed & \\
\hline &
\end{tabular}

Table 2: Distribution of respondents knowledge, causes and predisposing factors of malaria $(\mathrm{n}=500)$

\begin{tabular}{ll}
\hline Variables & Frequency (\%) \\
\hline Knowledge of malaria as a disease: & \\
Yes & $492(98.4)$ \\
No & 8 \\
Knowledge of causes of malaria: & $440(88.0)$ \\
Mosquito bite & $171(34.2)$ \\
Bad weather & $28(5.6)$ \\
Witchcraft & \\
Knowledge of symptoms of malaria: & $417(83.4)$ \\
Fever & $369(73.8)$ \\
Body ache & $243(48.6)$ \\
Chills and rigor & $82(16.4)$ \\
Vomiting & $463(92.6)$ \\
Knowledge of environmental factors predisposing to malaria: & $458(91.6)$ \\
Stagnant pools & $445(89.0)$ \\
Refuse & \\
Bush & $235(47.0)$ \\
Awareness of insecticide treated nets (ITN) & $265(53.0)$ \\
Yes & \\
No &
\end{tabular}


Publisher: African Networks on Ethnomedicines

Website: //http://journals.sfu.ca/africanem/index.php /AJID

http://dx.doi.org/10.4314/ajid.v6i2.1

Table 3: Distribution of respondents' practice of prevention against malaria.*

\begin{tabular}{llc}
\hline Variables & Frequency (\%) & \\
\hline & Yes & No \\
Protection of susceptible host from mosquito: & $494(98.8)$ & $6(1.2)$ \\
Use of insecticides & $356(71.2)$ & $144(28.8)$ \\
Manual killing & $164(32.8)$ & $336(67.2)$ \\
Use of mosquito coil & $275(55.0)$ & $225(45.0)$ \\
Use of bed nets & $63(12.6)$ & $431(87.4)$ \\
Use of repellent cream & $17(3.4)$ & $477(96.6)$ \\
Use of ITN & $115(23.0)$ & $397(77.0)$ \\
Use of window nets & $108(21.6)$ & $386(78.4)$ \\
Use of door nets & $229(45.8)$ & $265(54.2)$ \\
Control of breeding sites of mosquito: & & \\
Community environmental sanitation & $303(60.6)$ & $197(39.4)$ \\
$\quad$ on specific days & & \\
Bush clearing & $227(45.4)$ & $76(15.2)$ \\
Drainage of gutters & $224(44.8)$ & $79(15.8)$ \\
Clearing of refuse dump & 239 & $64(9.8)$ \\
\hline
\end{tabular}

*Multiple responses allowed

There is a statistically significant association between community participation in health talk and community participation in malaria control measures $(\mathrm{p}=0.000)$ as shown in Table 4 .

Table 4: Association between community health talk and community participation in malaria control

\begin{tabular}{|c|c|c|c|}
\hline Participation of community in health talk & \multicolumn{2}{|c|}{ Community participation in malaria control } & \multirow[t]{2}{*}{$\begin{array}{l}\begin{array}{l}\text { Statistics } \\
\text { (chi-square) }\end{array} \\
\end{array}$} \\
\hline Bush clearing & & & \\
\hline & Yes (\%) & No (\%) & \\
\hline Yes & 92 (40.5) & $19(25.0)$ & $p=0.000$ \\
\hline No & 27 (11.9) & $14(18.4)$ & \\
\hline No response & $108(47.6)$ & $43(56.6)$ & \\
\hline Total & $227(100.0)$ & $76(100.0)$ & \\
\hline \multicolumn{4}{|l|}{ Draining of gutters } \\
\hline Yes & 78 (34.8) & 33 (41.8) & $p=0.000$ \\
\hline No & $25(11.2)$ & $16(20.3)$ & \\
\hline No response & $121(54.0)$ & $30(38.0)$ & \\
\hline Total & $224(100.0)$ & $79(100.0)$ & \\
\hline \multicolumn{4}{|l|}{ Clearing of refuse dump } \\
\hline Yes & $77(32.2)$ & $34(53.1)$ & $\mathrm{p}=0.000$ \\
\hline No & 30 (12.6) & $11(17.2)$ & \\
\hline No response & $132(32.2)$ & 19 (29.7) & \\
\hline Total & $239(100.0)$ & $64(100.0)$ & \\
\hline
\end{tabular}

Table 5 shows there is statistical significant association between awareness of respondents about ITN and the usage of ITN $(\mathrm{p}=0.003)$.

Table 5: Association between awareness of ITN and usage of ITN

\begin{tabular}{lllll}
\hline & \multicolumn{3}{c}{ Usage of ITN } & Chi-square \\
\hline Awareness of ITN use & \multicolumn{1}{c}{ Yes } & & No & \\
No & $70(60.9 \%)$ & 165 & $(43.0 \%)$ & \\
Total & $45(39.1 \%)$ & 220 & $(57.0 \%)$ & $\mathrm{p}=0.003$ \\
\hline
\end{tabular}

Majority of the respondents had knowledge of malaria (98.4\%) with most respondents (88.0\%) believing that mosquito bite is the cause of malaria. This is similar to a study done at Igbonle and Idofin villages of Ibarapa local government areas of Oyo state which revealed that $70.5 \%$ believed that mosquito bite causes malaria (Sridhar et al., 2004). Also in a study conducted in Nike, in Enugu-East local government area, having the correct knowledge that mosquito bites transmit malaria was significantly influenced by level of education: 22 (19.8\%) for no education, 39 (35.1\%) for primary education, 59 (53.1\%) for secondary education and 51 (46.2\%) for post-secondary (Okeke and Okafor, 2008). Most of the respondents (94.8\%) had correct knowledge about the symptoms of malaria similar to what was found in a study conducted among urban dwellers in Benin city, Nigeria which showed that $92.5 \%$ had correct knowledge about malaria symptoms (Isah, 2007). This study found that, about $92.6 \%$ of the respondents believe that stagnant pool could predispose to malaria, $89.0 \%$ of the respondents believe 
Publisher: African Networks on Ethnomedicines

Website: //http://journals.sfu.ca/africanem/index.php /AJID

http://dx.doi.org/10.4314/ajid.v6i2.1

that bush in the environment is a predisposing factor to malaria. This shows that majority of the population have good knowledge of how environmental conditions could aid the growth of mosquito, this is similar to the result of a study carried out in Ibarapa local government area of Oyo state which showed $87.8 \%$ realized that surrounding water and vegetation promotes mosquito breeding (Sridhar et al., 2004).

Contrary to a study carried out by Shridar et al in Ibarapa, Nigeria which showed 51.3\% use bed nets for personal protection against mosquito bite (Sridhar et al., 2004), only 23.0\% of the respondents in this study use ITN for personal protection. Most of the respondents (53.0\%) in this study were not aware of ITN indicating a poor knowledge of this control measure in the control of malaria, however, a statistically significant association exists between the awareness of ITN and use of ITN as a protective measure. As ITN is now being promoted as the mainstay of the renewed push for malaria control, this finding is a bit worrisome. The poor awareness of ITN in this community under study may however, be due to the fact that ITN campaigns are yet to fully commence in Osun State and also because of the cost of ITN at the time of this study. There is a statistically significant association between respondent's participation in health talk and community participation in malaria control such as bush clearing, drainage of gutters and clearing of refuse dumps. This is similar to a study conducted in a malaria-affected district in Karnataka State, south India, where the exposed respondents to health education had significant increase in knowledge and change in attitude about malaria and its control strategies, especially on bio-environmental measures ( $p<0.001$ ) (Ghosh et al., 2006). This illustrates the effectiveness of utilizing health talk as a means of encouraging more involvement in malaria control measures.

\section{Conclusion}

It can be deduced from the study that the knowledge about malaria infection is high in the communities under study and so also is the level of community participation in its control since more than half of the respondents in the community participated in environmental control measures. Though ITN usage is low among the study population, there was significant association between awareness of insecticide treated nets (ITN) and its usage $(p<0.05)$. There were statistical significant association between community participation in health talk and community participation in malaria control $(\mathrm{p}<0.05)$. Hence there should be continuous awareness about advantages of participating in malaria control. Health education on malaria control should be reinforced especially through training and retraining of community health volunteers and to achieve a long term control of malaria, emphasis should be laid on elimination of the breeding sites of mosquitoes in the community.

\section{Acknowledgement}

The authors would like to appreciate the contributions of the students/research assistants and colleagues that made this survey possible.

\section{References}

1. Atkinson, J.-A., Bobogare, A., Vallely, A., Boaz, L., Kelly, G., Basifiri, W., Forsyth, S., Baker, P., Appleyard, B., Toaliu, H. and Williams, G. (2009). A cluster randomized controlled cross-over bed net acceptability and preference trial in Solomon Islands: community participation in shaping policy for malaria elimination. Malaria Journal, 8: 298.

2. Dias, J. C. (1998). [Community participation and control of endemic diseases in Brazil: problems and possibilities]. Cadernos de Saude Publica, 14: 19-37.

3. FMOH (2001). National Strategic Plan for Roll Back Malaria. Abuja, Federal Ministry of Health.

4. Ghosh, S., Patil, R., Tiwari, S. and Dash, A. (2006). A community-based health education programme for bio-environmental control of malaria through folk theatre (Kalajatha) in rural India. Malaria Journal, 5: 123.

5. Isah, E. C. (2007). Knowledge of malaria and the practice towards its control among urban dwellers in Benin City. Nigeria Postgraduate Medical Journal, 14: 125-128.

6. Kleinschmidt, I. (2001). Spatial statistical analysis, modelling and mapping of malaria in Africa. Faculty of Philosophy and Natural Sciences. Basel, University of Basel.

7. Mlozi, M. R. S., Shayo, E. H., Senkoro, K. P., Mayala, B. K., Rumisha, S. F., Mutayoba, B., Senkondo, E., Maerere, A. and Mboera, L. E. G. (2006). Participatory involvement of farming communities and public sectors in determining malaria control strategies in Mvomero District, Tanzania. Tanzania Health Research Bulletin, 8: 134-140.

8. Okeke, T. A. and Okafor, H. U. (2008). Perception and Treatment Seeking Behaviour for Malaria in Rural Nigeria: Implications for Control. Journal of Human Ecology, 24: 215-222.

9. Onwujekwe, O., Chima, R. and Okonkwo, P. (2000). Economic burden of malaria illness on households versus that of all other illness episodes: a study in five malaria holo-endemic Nigerian communities. Health policy (Amsterdam, Netherlands), 54: 143-159.

10. Onwujekwe, O., Hanson, K. and Fox-Rushby, J. (2004). Inequalities in purchase of mosquito nets and willingness to pay for insecticide-treated nets in Nigeria: Challenges for malaria control interventions. Malaria Journal, 3: 6.

11. Rojas, W., Botero, S. and Garcia, H. I. (2001). An integrated malaria control program with community participation on the Pacific Coast of Colombia. Cadernos de Saude Publica, 17: S103-S113.

12. Sachs, J. and Melaney, P. (2002). The economic and social burden of malaria. Nature, 415: 680-685.

13. Schapira, A. (2004). Malaria. In Heymann, D. L. (Ed.) Control of Communicable Diseases Manual. 18 ed. Washington, DC, USA, American Public Health Association.

14. Sridhar, M. K. C., Adeniyi, J. D., Brieger, W. R., Oyediran, A. B. O. and Demissie, P. (2004). Malaria control: lessons learned from a community-based study in Nigeria.

15. WHO (2002). Reducing risks, promoting healthy life. The World Health Report. Geneva, World Health Organization. 